services were unknown, the danger of the spread of infection was small, and the routine malaria control was considered sufficient. But since the outbreak of war, the establishment of large garrisons and the increase of air and sea traffic between the islands has greatly increased the danger of introducing malaria to the 'clean' islands. It is no longer safe to rely on quarantine measures; so steps are to be taken to eliminate possible places where Anopheles might breed.

Entomological surveys are to be made near shores and ports, and reconnaissance surveys of all potential breeding grounds. Normal anti-mosquito work will be intensified and danger places will be cleared, drained and oiled where necessary. At the same time an engineer will prepare a scheme for mosquito control on a long-term basis. The financial grant will cover the cost of plant, such as transport vehicles, garages, laboratories, equipment and tools, and the salaries of an engineer, surveyors, overseers, clerks, drivers and labourers for a period of three years. The measures to be taken will also wipe out the mosquitoes, other than Anopheles, already present in Fiji, which are carriers of such diseases as dengue fever and filariasis, and which would be a serious menace if yellow fever should ever be introduced to the territory.

\section{Dehydrated Graphite Sols}

DILUTE solutions of aqueous colloidal graphite have proved of service by their ready formation of electrically conductive, lubricative and opaque films (see Nature, 149, 298; 1942). Bernard H. Porter, 25 South Street, Houlton, Maine, states that highly concentrated dispersions of the same colloid, compressed and dehydrated, constitute effective smallparts substitutes for metal. Irreversible in character, dehydrated masses of colloidal graphite are electrically conductive, markedly resistant to high temperatures, chemically inert, gas absorbent and easily machined. The commercial form of graphite hydrosol is slowly baked in pressure moulds at $90^{\circ} \mathrm{C}$. Shrinkage may be so high as 85 per cent by volume. The resistivity of dehydrated graphite baked at $105^{\circ} \mathrm{C}$. without pressure is $\mathbf{2 8 . 2 1} \mathrm{ohm}-\mathrm{cm}$.; its porosity 24.93 per cent. Bars having greater conductivity than the graphite alone are formed by embedding strands of No. 30 copper wire, or strips of 60-mesh screen, in the graphite paste before baking. Metallic dusts may be admixed for the same purpose, though not without decreasing the tensile strength of the dried solid. Machine shaping, tapping and threading may follow as desired. Guard rings, connectors, electrodes, contacts, special-purpose forms and small parts normally made of metal are applications for dehydrated graphite sols.

\section{Teletypewriter Test Sets}

Distormons in teletypewriter signals are classified in three groups : bias, characteristic distortion, and fortuitous distortion. Bias, due to asymmetry in the circuit, causes all marking impulses to be lengthened or shortened. The increase or decrease is substentially equal in all the marking impulses, and the amount of bias is the lengthening or shortening expressed as a percentage of the unit pulse. As interpreted by a teletypewriter, the lengthening or shortening is what it would be if the bias affected only the beginnings of the marking impulses. Characteristic distortion differs from bias in that the amount of the distortion may vary from impulse to impulse and is dependent on the combination of the preceding impulses. Fortuitous distortion is normally nonrepetitive and is caused by random interference such as cross-fire, lightning or power induction.

A teletypewriter test set has been developed by the Teletype Corporation (U.S.A.), which transmits code impulses corresponding to teletypewriter characters and distorts their timing relative to the start pulse by segments on two concentric rings over which conducting brushes are motor-driven at a constant speed. By adjusting the outer ring with respect to the inner one and connecting the segments of the two rings either in series or parallel, signals may the produced with any desired amount of marking or spacing bias, or marking or spacing end distortion. An article by W. Y. Lang (Bell Lab. Rec., 21, No. 12 ; August 1943) describes and illustrates the set.

\section{Directory of Natural History Societies}

A "Directory of Natural History Societies" in Great Britain and Ireland is now in course of prepara. tion for publication by the Amateur Entomologists' Society in the near future. Its aim is to make known the existence and work of societies interested in any branch of natural history (except economic, agricultural or medical problems). The compilers wish to include as large a number of such organizations now existing in Great Britain and Ireland as can be brought to their notice, from national associations and regional unions to county, town, university or school societies. Names and addresses of as many organizations as possible, particularly of the smaller clubs and societies not affiliated to any naturalists' union, school or college organizations, and the like, are now needed, and the compilers will be glad of any help that readers can give. Postcards or letters should be addressed to Mr. W. G. Rawlings, 14 Westfield Park, Bath.

\section{Merseyside Fauna and Flora}

THERE is much that has more than a local interest in the recently issued Portfolio Vol. 2 of the Merseyside Naturalists' Association, covering mainly field work in 1942. From the botanical interest, J. D. Massey discusses in a lengthy paper the changes in the flora of the Liverpool area from 1838 to 1943 , during which period fifty-nine plants have become extinct, forty-six native British species have become naturalized in the district, there have been seventyeight naturalized alien incomers, while some 250 casuals have been recorded. The flora of this district is specially interesting from the influence of shipping introductions, of industrial slag heaps, building, drainage and pollution. Eric Hardy has a note, with photographs, of a large and well-established sycamore tree (Acer pseudo-platanus) growing entirely parasitically from a cleft in an alder tree (Alnus glutinosa) at Ince Blundell, South Lancashire. T. Edmondson has a survey of the avi-fauna of a mile-long colliery lake at Leigh with 109 birds, comprising forty residents, eleven summer visitors, fourteen passage migrants, twelve winter visitors and thirty-two occasional visitors, including such interesting species as gadwall, pintail, Bewick's swan, goosander, smew, bittern, red-necked phalarope; from the migration of waders and duck, it may be part of a route across the north of England, G. C. Miller has made some detailed and statistical studies of the nesting of the house sparrow, Passer d. domesticus, in which 